\title{
Multi-criteria risk classification to enhance complex supply networks performance
}

\author{
Silvia Carpitella ${ }^{1}$ (D) Ilyas Mzougui $^{2} \cdot$ Joaquín Izquierdo $^{3}$ (D)
}

Accepted: 21 August 2021 / Published online: 2 November 2021

(c) Operational Research Society of India 2021

\begin{abstract}
Management of complex supply networks is a fundamental business topic today. Especially in the presence of many and diverse stakeholders, identifying and assessing those risks having a potential negative impact on the performance of supply processes is of utmost importance and, as a result, implementing focused risk management actions is a current lively field of research. The possibility of supporting Supply Chain Risks Management (SCRM) is herein explored from a Multi-Criteria Decision-Making (MCDM)-based perspective. The sorting method ELimination Et Choix Traduisant la REalité (ELECTRE) TRI is proposed as a structural procedure to classify Supply Chain Risks (SCRs) into proper risk classes expressing priority of intervention so as to ease the implementation of prevention and protection measures. This approach is intended to offer structured management insights by means of an immediate identification of the most highly critical risks in a wide set of previously identified SCRs. A real-world case study in the field of the automotive industry is implemented to show the applicability and usefulness of the approach.
\end{abstract}

Keywords Supply chain risk $\cdot$ Supply chain management $\cdot$ Multi-criteria decisionmaking $\cdot$ ELECTRE TRI

Silvia Carpitella

carpitella@utia.cas.cz

Ilyas Mzougui

ilyas.mzougui@gmail.com

Joaquín Izquierdo

jizquier@upv.es

1 Department of Decision-Making Theory, Institute of Information Theory and Automation, Czech Academy of Sciences, Prague, Czech Republic

2 Faculty of Sciences and Technologies, Abdelmalek Essaadi University, Tangier, Morocco

3 Institute for Multidisciplinary Mathematics, Universitat Politècnica de València, Valencia, Spain 


\section{Introduction and research objectives}

Supply Chains (SCs) are complex global networks enabling companies to increase their competitive advantage and flexibility as well as to reduce costs by means of a wide range of possibilities in terms of suppliers selection [15]. Managing SC networks is an extremely delicate task requiring the integration of suitable models aimed at minimising losses while optimising sustainability, as well as best practices of risk management, by making use of proper computational tools [50]. The fundamental part played by SCs as main mechanisms to provide, produce, store, and deliver products to consumers is widely recognised [20]. In this context, Supply Chain Management (SCM) is aimed at optimising the whole set of supply assets and flows (for example financial aspects, information flow, raw materials and finite products) participating in business results [13]. The main objective of SCM consists in globally increasing the generated value by simultaneously maximising gains and minimising costs. SCM is considered one of the most important aspects related to the management of complex industrial systems [11], since it allows to build strategies for gaining sustainable competitive advantages by reducing costs without compromising customers' satisfaction [47]. To such an aim, effective risk management is essential [41] and some previous comprehensive evaluation of all the potential supply chain risks (SCRs) is indispensable to make SCM successful in practice [52]. Complex interactions among all the involved stakeholders such as manufacturers, suppliers and retailers make indeed SCs susceptible to diverse risks [51] depending on multiple aspects, sometimes conflicting with each other. In this context, a multi-criteria decision-making (MCDM) approach represents an effective support for the stage of SCR assessment. This is related to the formal identification of the most relevant aspects (i.e. criteria) involved in the SCR management (SCRM) discipline, whose importance can be established by means of the help of a panel of experts in the field of interest.

The formal objective of this research consists in identifying within a wider set of SCRs, those having a stronger negative impact on the SCM process by taking into consideration current challenges and circumstances (i.e. world economy conjunctures and conflicts in international relations, COVID-19 constraints, and so on). To this aim, SCRs will be classified into risk classes by applying the sorting MCDM method ELimination Et Choix Traduisant la REalite (ELECTRE) TRI. ELECTRE TRI has been extensively applied in the existing literature to treat similar decision-making problems on supply chain risk management, something that confirms its suitability for the field of reference. However, to the best of the authors' knowledge, it is the first time that the technique is proposed for sorting supply chain risks connected to the sector of the developed case study, that is the automotive industry, into priority classes by means of the set of criteria herein considered, including the strategic impact.

The paper is organised as detailed next. Section 2 presents a literature review on the main topics of research. Section 3 describes the proposed method which will be practically applied to a real-world case study. Practical managerial 
insights will be discussed and analysed in Sect. 4. Lastly, Sect. 5 provides the conclusions of the work along with possible future lines of development.

\section{Literature review}

\subsection{Current challenges for supply chain risk management}

Given the primary role of SCM for business, industries have developed several strategies oriented to SC costs reduction and efficiency enhancement by adopting such techniques as Just In Time (JIT) procedures, which have been demonstrated to increase productivity [23]. As affirmed by Yang et al. [80], a JIT supply chain brings uncountable advantages to companies and should be based on the acquisition of customer knowledge to be ideally shared among SC stakeholders. JIT-based strategies can indeed guarantee cost flexibility and reveal to be particularly helpful to capture economies of scale [35]. However, this may lead to higher SC complexity as well as vulnerability to failures, which would be translated into the exposure of companies to the occurrence of several SCRs [73, 78] responsible of serious financial losses $[56,77]$.

As discussed in a previous contribution Carpitella et al. [8], implementing strategies aimed at protecting from disruptions is the most important objective to be pursued for effectively managing complex networks [4, 29, 36, 43]. Moreover, the adaptation capability of networks should be enhanced with respect to possible variations of initial established conditions, not necessarily facing disruption, but with the objective of increasing communication and information exchange through the network. It is then clear as SCRM represents a key factor for enterprises [42] aimed at minimising potential losses by developing efficient plans for identifying, assessing, treating and continuously monitoring the main SCRs [31, 58, 79]. Aiming at facilitating SCRM, companies need to promote intra and inter firm integration [56] by establishing reliable collaboration among supply chain partners. Integration enables the circulation of important information about risks and helps SC stakeholders in quickly responding to possible disruptions [44]. Several studies have been undertaken on the topic of SCRM; however, the stage of risks identification is quite hard, and this is somehow due to gaps in the literature [19]. In any case, SCRs are difficult to identify in a unique manner mainly because of their complex and multifaceted nature $[31,70]$.

One has to observe as SCRM is nowadays facing huge challenges due to the outbreak of the COVID-19 pandemic. Global economic forces are currently changing global trade landscapes and struggling to manage various kinds of SC perturbation. New policies based on the implementation of rigid health protocols are confirming to be essential for long-term SC sustainability [34]. On the whole, Habib et al. [27] state that the way the COVID-19 has halted normal life has no precedent in modern history, and dramatic shocks have been caused to supply chains by economic and societal lockdown. Such an outbreak is undoubtedly having a devastating impact on the global economy [69] and the possibility of another dangerous financial recession 
with severe disruptions is expected to negatively impact many SCs for the upcoming months [28].

\subsection{Supply chain risk assessment}

Existing approaches in the literature show as SCR identification and assessment strictly depend on the domain of analysis and on the perspective of the study [1]. Despite risks change from a study to another according to risk categories and the related evaluation criteria, they, however, present similarities [33]. Many articles classify risks into two categories: internal SCRs and external SCRs [1,33]. Such authors as Rostamzadeh et al. [64], Fan and Stevenson [19], Louis and Pagell [46] add a third category of SCRs, namely risks internal to firms but external to supply chains. A further SCR category has been recently considered [56], generated from relationships with customers.

Risks in supply chain centers mainly refer to disruption of flows, and disruptions happen because of the presence of multiple sources [59] such as regulatory changes, relations with customers and suppliers [21], issues related to labor and workers [32], logistic providers and forecasting errors [21], machine breakdown, inventory shortage, IT malfunctioning, natural disasters, terrorist attacks [72], geopolitical risks [75], environmental problems, health and safety risks [14, 31], cultural divergences $[3,33]$, and so on. In this context, it is also important to highlight the need of developing models for supplier selection and order allocation, as they can provide helpful tools leading towards the implementation of suitable procurement strategies capable to deal with diverse critical risks [62]. A fully integrated strategic approach of risk management is certainly crucial to supply chains and, as underlined in Creazza et al. [17], this process has to be promptly and proactively addressed without waiting for actual risk occurrence. Furthermore, as expressed in Raihan et al. [61], a rich collection of works focused on supply chain risk management stresses the need of effectively addressing vagueness in industrial supply chains by assessing risks from different perspectives. A significant aspect to be taken into account in such a field of analysis is indeed represented by uncertainty characterising demand and supply [49].

As we underlined in a previous research [57], traditional methods of risk assessment as those based on Failure Modes, Effects and Criticality Analysis (FMECA) [16] are particularly effective to obtain a general and complete overview of risk management and prevention [71]. FMECA-based approaches lead indeed to consistent benefits by carrying out a thorough risk evaluation aimed at globally enhancing SC performance [18] and quality [22]. FMECA-based procedures have been implemented also as a part of sustainability risk management framework, by means of the identification of major SCRs across three dimensions assumed for sustainability, namely economic, social and environmental aspects [24].

The stage of SCR identification represents then a fundamental and complex part of the entire SCRM process and complexity, and uncertainty increase when it comes to the next stage of risk SCRs assessing. As previously stated, MCDM methods can 
be useful to cope with the various analysed difficulties, since they are tools able to handle major barriers in analysing risks [1].

\subsection{Multi-criteria decision-making approaches in supply chain risk management}

MCDM methods effectively support a plethora of decision problems, and their crucial role has been widely acknowledged [37]. The final decision depends on various evaluation criteria, that sometimes are mutually dependent and conflicting with each other. MCDM methods have the ability of going towards the solution that satisfies the multiple aspects involved with regard to their mutual importance. MCDM methods are capable of managing both qualitative and quantitative aspects when an evaluation concerning a set of alternatives is required [55].

The MCDM method most commonly used in the literature to assess and manage SCRs is the Analytic Hierarchy Process (AHP) [6, 21, 68]. However, due to the fact that AHP cannot take into account vagueness and uncertainty affecting input data, the fuzzy AHP (FAHP) has been used in several studies for SCRM [38, 60, 65, 66]. As demonstrated by such authors as Bharsakade et al. [5], this method is particularly effective for planning strategic management practices by transforming qualitative judgments affected by vagueness into quantitative data in a structured way. Other MCDM methods have been combined and proposed for the problem under analysis. Samvedi et al. [67] integrate AHP and the Technique for Order of Preference by Similarity to Ideal Solution (TOPSIS) for evaluating SCRs. Heidari et al. [30] propose to extend the same approach to a fuzzy environment in order to overcome the limitation of using crisp values. However, the need to take into account the causeeffect relationships among criteria, as well as among SCRs [26], has encouraged researchers to use the fuzzy DEcision MAking Trial and Evaluation Laboratory (DEMATEL) method to handle SCRM. For instance, Muhammad and Cavus [54] evaluate the relationships bonding twelve criteria with relation to learning management systems. Chang and Cheng [12] apply the fuzzy DEMATEL to highlight influential factors in evaluating suppliers.

As one can note, several MCDM methods have been proposed in the existing literature, each one being characterised by specific procedures and objectives. MCDM methods can effectively support in achieving the following objectives [8]: selecting the best solution among various options, ranking alternatives to establish their weights and/or to draw up a list of priorities [76], sorting alternatives into different groups on the basis of their common characteristics [10]. ELECTRE methods can provide effective results by performing precise analyses over a diverse set of alternatives [2] and have been proved capable to deal with complex decision-making problems related to the topic of supply chain risk management [74]. In particular, ELECTRE TRI has been applied to various application fields and its main advantage with respect to other ranking-based MCDM methodologies consists in the possibility of sorting alternatives into predefined and ordered classes, on the basis of their common features [9]. This approach is an effective alternative procedure with respect to the traditional ranking that it is possible to achieve by means of other approaches, as it enables to effectively support the analyst [25] in identifying which set of supply 
chain risks may have a critical impact on the general level of performance according to the evaluation of a plethora of criteria [74]. This view aims to ease the execution of risk management intervention by promoting a more efficient process of risk assessment [39]. For all these reasons, the ELECTRE TRI technique is herein proposed as a sorting MCDM method to group SCRs into risk classes according to the evaluation of suitable criteria, something that will enable to simultaneously take into account uncertainty affecting input evaluations.

\section{Materials and methods}

MCDM methods do not guarantee the achievement of optimal solutions. Final results can be considered as the best trade-off under given conditions, namely the established set of criteria, their mutual importance, the evaluations of alternatives under those criteria and, in the case of ELECTRE TRI, the parameters specifically set for running the technique. Furthermore, it is important to underline as the support of decision-makers expert in the field is crucial and they will have to eventually agree with the final outputs to confirm their validity and feasibility. Dealing with human judgments, MCDM applications are indeed always affected by human subjectivity. However, they allow to derive practical results reflecting valuable managerial experience by means of reliable mathematical tools. As already observed, ELECTRE TRI allows to treat uncertainty of input evaluations even if not in an absolute sense. In the present paper, we propose to lead a sensitivity analysis on some of the most important parameters characterising the methodological approach, in order to represent a wide range of situations.

\subsection{The ELECTRE TRI sorting method}

ELECTRE TRI is applied by performing two consecutive main stages [9]. The first stage consists in developing outranking relations based on concordance and discordance principles. The defined relations are then exploited during the second stage to sort alternatives to classes, according to their common features. The assignment can be carried out through two different procedures. Before carrying out the application, the following input data have to be organised: set of evaluation criteria $B_{k}$, under which alternatives have to be evaluated; criteria weights $w_{k}$, expressing mutual importance of criteria; set of reference profiles $P_{j}$, each one characterised by specific evaluations under each criterion and defined by two limits $p_{h}$ and $p_{h+1}$; set of classes $C_{h}$ identified by reference profiles; set of alternatives $A_{i}$ with the related evaluations $B_{k}\left(A_{i}\right)$ assumed under each criterion; a threshold value $\lambda$ comprised between 0.5 and 1 , known as cutting level and needed to complete the first stage of ELECTRE TRI; values of indifference, strong preference and veto thresholds, namely $I_{k}, S_{k}$, and $V_{k}$, related to the outranking relations. $I_{k}$ represents the minimal difference to declare preference between a pair of elements, $S_{k}$ is the minimal difference to declare strong preference between a pair elements, and $V_{k}$ is the minimal difference highlighting a relation of incompatibility between a pair of elements [7]. 
The first stage consists in establishing an outranking relation comparing each alternative with limits of classes, that is with the reference profiles. The following main steps have to be implemented consecutively.

- Calculating partial concordance indices for each criterion. Each alternative $A_{i}$ is pairwise compared with the defined reference profiles $P_{j}$, and concordance indices, noted as $C_{k}\left(A_{i}, P_{j}\right)$, are calculated for each criterion $B_{k}$ by using formula (1).

$$
C_{k}\left(A_{i}, P_{j}\right)=\left\{\begin{array}{l}
1 \quad \text { if }\left[B_{k}\left(P_{j}\right)-B_{k}\left(A_{i}\right)\right] \leq I_{k} \\
0 \text { if }\left[B_{k}\left(P_{j}\right)-B_{k}\left(A_{i}\right)\right] \geq S_{k} . \\
\frac{B_{k}\left(A_{i}\right)-B_{k}\left(P_{j}\right)+S_{k}}{S_{k}-I_{k}} \text { otherwise }
\end{array}\right.
$$

The aggregated concordance index $C\left(A_{i}, P_{j}\right)$ are then derived by aggregating and weighting the concordance indices for each criterion in the following way:

$$
C\left(A_{i}, P_{j}\right)=\frac{\sum_{k=1}^{K} w_{k} \cdot C_{k}\left(A_{i}, P_{j}\right)}{\sum_{k=1}^{K} w_{k}} .
$$

- Calculating partial discordance indices for each criterion by using (3).

$$
D_{k}\left(A_{i}, P_{j}\right)=\left\{\begin{array}{l}
1 \quad \text { if }\left[B_{k}\left(P_{j}\right)-B_{k}\left(A_{i}\right)\right]>V_{k} \\
0 \text { if }\left[B_{k}\left(P_{j}\right)-B_{k}\left(A_{i}\right)\right] \leq S_{k} . \\
\frac{B_{k}\left(P_{j}\right)-B_{k}\left(A_{i}\right)-S_{k}}{V_{k}-S_{k}} \text { otherwise }
\end{array}\right.
$$

- Calculating outranking credibility indices through formula (4).

$$
\delta\left(A_{i}, P_{j}\right)=C\left(A_{i}, P_{j}\right) \cdot \frac{\prod_{k \in K^{*}}\left(1-D_{k}\left(A_{i}, P_{j}\right)\right)}{1-C\left(A_{i}, P_{j}\right)},
$$

$K^{*}$ being the subset of criteria for which $D_{k}\left(A_{i}, P_{j}\right)>C\left(A_{i}, P_{j}\right)$. When the veto threshold is not established, the credibility index $\delta\left(A_{i}, P_{j}\right)$ is assumed as equal to the aggregated concordance index $C\left(A_{i}, P_{j}\right)$.

- Exploiting the specific kind of outranking relation by using the cutting level $\lambda$. Specifically, $\lambda$ represents the threshold value for $\delta\left(A_{i}, P_{j}\right)$ to accept the hypothesis that $A_{i}$ outranks $P_{j}$. The value of $\lambda$ is comprised between 0.5 and 1 and should be greater than the quantity equal to $1-$ (highest weight/total weigh) $[45,48]$. The framework to establish outranking relations is shown in Fig. 1, in which $\boldsymbol{R}, \boldsymbol{S}$ and $I$ respectively express incompatibility, preference and indifference relations.

The second stage consists in assigning alternatives to classes by means of two possible procedures, that are the pessimistic and the optimistic rules, described in the following. In general, the pessimistic procedure has to be preferred to the optimistic rule, tending to assign alternatives to classes defined by a lower profile, this way guaranteeing the achievement of more conservative results. According to the pessimistic (or conjunctive) procedure, alternative $A_{i}$ is assigned to the class $C_{h}$ for 


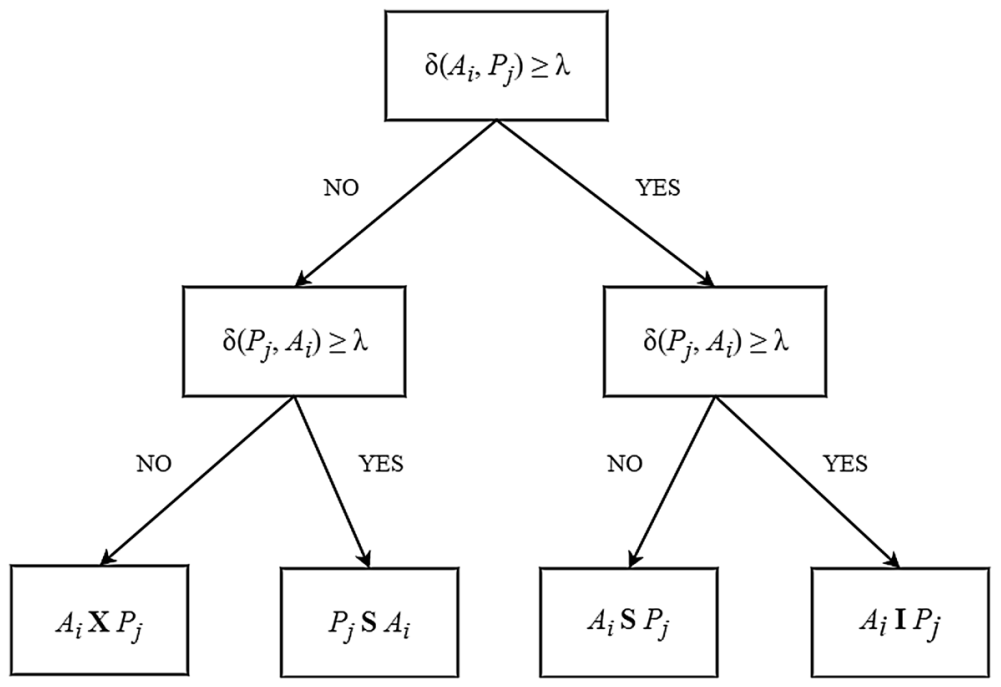

Fig. 1 Framework to establish outranking relations

which the condition that $A_{i} S P_{j}$ is verified. The procedure is made of two steps: (1) comparing successively each alternative with the limits of classes: $A_{i}$ is successively compared to the profiles defining the classes until condition $A_{i} S P_{j}$ is verified; (2) assigning alternative $A_{i}$ to class $C_{h+1}$. According to the optimistic (or disjunctive) procedure, alternative $A_{i}$ is assigned to the class $C_{h}$ for which the condition that $P_{j} S$ $A_{i}$ is verified. The procedure is made of two steps: (1) comparing successively each alternative with the limits of classes: $A_{i}$ is successively compared to profiles defining classes until condition $P_{j} S A_{i}$ is verified; (2) assigning alternative $A_{i}$ to class $C_{h}$.

\subsection{Real-world case study: presentation and application}

The present case study refers to a company operating in the sector of the automotive industry. The choice of this sector is justified by the fact that, as expressed by Kumar et al. [40], it has been facing many complex challenges connected to unpredictable demand evolution, rigid legislation, quick technological updates, as well as changes in global mobility patterns. Our aim is to sort alternatives belonging to a set of twenty-three SCRs $\left(A_{i}, i=1, \ldots, 23\right)$ into four ordered risk classes $\left(C_{1}=\mathrm{D}, C_{2}=\mathrm{C}, C_{3}=\mathrm{B}\right.$ and $\left.C_{4}=\mathrm{A}\right)$ expressing priority of intervention. Classes have been ordered from class $\mathrm{D}$ to class $\mathrm{A}$ to express the transition from a condition of low priority to a condition of high priority of intervention in terms of risk prevention/mitigation. These classes highlight the global priority required to manage SCRs according to specific intervals of values assumed by the chosen criteria. The following evaluation criteria are considered: $B_{1}$, occurrence; $B_{2}$, dependence; $B_{3}$, cost; $B_{4}$, strategic impact. SCRs have been evaluated under each criterion by involving a decision-making group, and their evaluations have been 
translated into numerical values ranged within the interval [1, 5]. Figure 2 shows the four ordered classes delimited by three reference profiles with relation to the three evaluation criteria.

The input evaluations, available from the previous research [57], are synthesised in Table 1. We herein recall the obtained vector of criteria weights $\mathbf{w}=[0.0679,0.3899,0.3899,0.1523]$. However, we specify that, instead of ranking risks, we are now interested in sorting them into classes by means of ELECTRE TRI as a structured methodology easily dealing with big numbers of alternatives. In these types of situations, indeed, relying on the possibility of sorting risks into priority classes, instead of obtaining a plain ranking, can be useful to immediately highlight those sets of risks in need of urgent improvement. Also, the nature of this need can be easily distinguished on the basis of common characteristics.

As underlined by Mousseau et al. [53], threshold values have to be fixed by the decision-maker to properly set the methodology according to the specific requirements of study. Larger values can be first attributed to thresholds and then progressively reduced until considered appropriate for each criterion. The preference and indifference thresholds have been herein assumed as a half and a quarter of the width of the classes (i.e. respectively equal to 0.5 and 0.25 ), whereas veto threshold as equal to the width of the classes (i.e. equal to 1). Results obtained by means of the pessimistic and optimistic rules are respectively shown in Tables $2 \mathrm{a}$, b. The assignment of each SCR to the defined classes has been achieved by varying the cutting level $\lambda$ within the range $[0.5,1]$.

As previously discussed, the pessimistic procedure is in general preferred to the optimistic procedure, because it tends to assign alternatives to classes defined by a lower profile. In this sense, the pessimistic procedure is considered more conservative. However, in the present case study, the most cautious attitude consists in assigning SCRs to classes defined by higher profiles, the last ones highlighting a need of high priority of intervention. For example, we can observe as SCR $R_{1}$ (improper raw materials) is assigned to class C (medium-low priority) by the pessimistic rule and to class A (high priority) by the optimistic rule. In this case, dealing with risk management, we prefer the procedure that do not

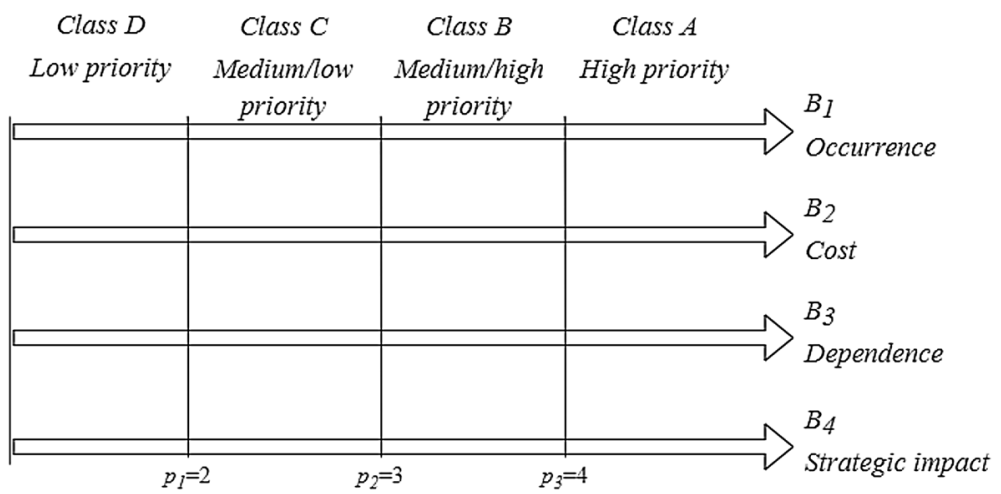

Fig. 2 Classes and profiles over evaluation criteria 
Table 1 Input data for the ELECTRE TRI application

\begin{tabular}{|c|c|c|c|c|c|}
\hline SCR & Risk description & $B_{1}$ & $B_{2}$ & $B_{3}$ & $B_{4}$ \\
\hline$R_{1}$ & Improper raw materials & 4.60 & 2.00 & 4.20 & 3.80 \\
\hline$R_{2}$ & Sudden design changes & 2.80 & 1.00 & 3.60 & 2.80 \\
\hline$R_{3}$ & Information exchange & 2.40 & 3.00 & 3.00 & 3.60 \\
\hline$R_{4}$ & Requirement accomplishment & 2.80 & 5.00 & 2.80 & 3.40 \\
\hline$R_{5}$ & Ineffective transport & 3.40 & 4.00 & 3.80 & 3.40 \\
\hline$R_{6}$ & Transport network lengthening & 2.60 & 3.00 & 3.20 & 3.40 \\
\hline$R_{7}$ & Taxes increase & 2.60 & 1.00 & 3.40 & 4.00 \\
\hline$R_{8}$ & Raw material market prices increase & 3.20 & 2.00 & 3.80 & 3.20 \\
\hline$R_{9}$ & Equipment or production facilities breakdown & 2.00 & 3.00 & 3.80 & 2.80 \\
\hline$R_{10}$ & Production performance & 2.80 & 4.00 & 3.80 & 3.00 \\
\hline$R_{11}$ & Human resource (HR) attitude & 2.40 & 2.00 & 3.60 & 3.60 \\
\hline$R_{12}$ & Insufficient manufacturing capacity or capability & 2.60 & 4.00 & 3.20 & 3.00 \\
\hline$R_{13}$ & Labor and production costs increase & 2.20 & 2.00 & 4.00 & 4.00 \\
\hline$R_{14}$ & Production breakdown & 3.00 & 2.00 & 3.20 & 3.40 \\
\hline$R_{15}$ & Production disruption & 2.40 & 3.00 & 3.20 & 4.00 \\
\hline$R_{16}$ & Matching supplier requirements & 3.00 & 2.00 & 3.00 & 3.00 \\
\hline$R_{17}$ & Facilities, HR, policies and processes breakdown & 2.40 & 5.00 & 3.20 & 3.80 \\
\hline$R_{18}$ & Inadequate reconfiguration of manufacturing processes & 2.60 & 4.00 & 3.40 & 3.40 \\
\hline$R_{19}$ & Inefficient delivery of products & 3.00 & 3.00 & 4.00 & 3.80 \\
\hline$R_{20}$ & Supply chain disruptions due to natural disasters & 2.20 & 5.00 & 4.20 & 3.60 \\
\hline$R_{21}$ & Supply chain disruptions due to events of terrorism & 1.60 & 1.00 & 3.20 & 4.00 \\
\hline$R_{22}$ & Social unrest in region where the supply chain operates & 2.00 & 2.00 & 3.20 & 4.20 \\
\hline$R_{23}$ & Dependence on suppliers & 2.80 & 2.00 & 3.80 & 4.20 \\
\hline
\end{tabular}

underestimate the possible impact of a given risk. This is the main reason why, according to the semantic meaning of classes, we prefer adopting the results derived through the optimistic procedure.

For the sake of completeness, aiming at studying the influence of the thresholds on the final assignment, Table 3 shows results derived by the adopted optimistic procedure by varying the veto threshold. Specifically, with respect to the application of Table 2, more strict and less strict conditions have been represented. First, Tables $3 \mathrm{a}, \mathrm{b}$ respectively show results obtained by fixing a veto threshold respectively equal to 0.5 and 0.75 times the width of the classes. Then, tables $3 \mathrm{c}$ and $3 \mathrm{~d}$, respectively, show results obtained by fixing a veto threshold respectively equal to 1.25 and 1.5 times the width of the classes. In the four cases, values assumed by indifference and preference thresholds have been modified accordingly.

By observing the results in Table 3, one can note that larger values of the veto thresholds globally lead to assign SCRs to classes characterised by lower priority of intervention. On the contrary, lower values of the veto thresholds lead to assign SCRs to higher classes. 
Table 2 Assignment of SCRs to classes by means of ELECTRE TRI

\begin{tabular}{|c|c|c|c|c|c|c|c|c|c|c|c|c|c|}
\hline $\mathrm{SCR} / \lambda$ & 0.50 & 0.60 & 0.70 & 0.80 & 0.90 & 1.00 & $\mathrm{SCR} / \lambda$ & 0.50 & 0.60 & 0.70 & 0.80 & 0.90 & 1.00 \\
\hline \multicolumn{7}{|c|}{ (a) Pessimistic procedure } & \multicolumn{7}{|c|}{ (b) Optimistic procedure } \\
\hline$R_{1}$ & $\mathrm{C}$ & $\mathrm{C}$ & $\mathrm{C}$ & $\mathrm{C}$ & $\mathrm{C}$ & $\mathrm{C}$ & $R_{1}$ & B & B & B & B & B & A \\
\hline$R_{2}$ & $\mathrm{D}$ & $\mathrm{D}$ & $\mathrm{D}$ & $\mathrm{D}$ & $\mathrm{D}$ & $\mathrm{D}$ & $R_{2}$ & $\mathrm{C}$ & $\mathrm{C}$ & B & B & B & B \\
\hline$R_{3}$ & B & $\mathrm{B}$ & B & B & B & $\mathrm{C}$ & $R_{3}$ & B & B & B & B & B & B \\
\hline$R_{4}$ & B & B & B & B & B & B & $R_{4}$ & A & A & A & A & A & A \\
\hline$R_{5}$ & A & A & A & $\mathrm{B}$ & $\mathrm{B}$ & $\mathrm{B}$ & $R_{5}$ & A & A & A & B & B & B \\
\hline$R_{6}$ & B & B & B & B & B & C & $R_{6}$ & B & B & B & B & B & B \\
\hline$R_{7}$ & $\mathrm{D}$ & $\mathrm{D}$ & $\mathrm{D}$ & $\mathrm{D}$ & $\mathrm{D}$ & $\mathrm{D}$ & $R_{7}$ & B & B & B & B & B & B \\
\hline$R_{8}$ & $\mathrm{C}$ & $\mathrm{C}$ & $\mathrm{C}$ & $\mathrm{C}$ & $\mathrm{C}$ & $\mathrm{C}$ & $R_{8}$ & $\mathrm{C}$ & $\mathrm{C}$ & B & B & B & B \\
\hline$R_{9}$ & $\mathrm{C}$ & $\mathrm{C}$ & $\mathrm{C}$ & $\mathrm{C}$ & $\mathrm{C}$ & $\mathrm{C}$ & $R_{9}$ & $\mathrm{C}$ & $\mathrm{C}$ & B & B & B & B \\
\hline$R_{10}$ & B & B & B & B & B & B & $R_{10}$ & B & B & B & B & B & B \\
\hline$R_{11}$ & $\mathrm{C}$ & C & C & C & $\mathrm{C}$ & $\mathrm{C}$ & $R_{11}$ & B & B & B & B & B & B \\
\hline$R_{12}$ & B & B & B & B & B & $\mathrm{C}$ & $R_{12}$ & B & B & B & B & B & B \\
\hline$R_{13}$ & $\mathrm{C}$ & $\mathrm{C}$ & $\mathrm{C}$ & $\mathrm{C}$ & $\mathrm{C}$ & $\mathrm{C}$ & $R_{13}$ & B & B & B & B & B & B \\
\hline$R_{14}$ & $\mathrm{C}$ & C & C & C & C & C & $R_{14}$ & $\mathrm{C}$ & C & C & C & $\mathrm{C}$ & B \\
\hline$R_{15}$ & B & B & B & B & B & $\mathrm{C}$ & $R_{15}$ & B & B & B & B & B & $\mathrm{C}$ \\
\hline$R_{16}$ & $\mathrm{C}$ & $\mathrm{C}$ & $\mathrm{C}$ & $\mathrm{C}$ & $\mathrm{C}$ & $\mathrm{C}$ & $R_{16}$ & $\mathrm{C}$ & $\mathrm{C}$ & $\mathrm{C}$ & $\mathrm{C}$ & $\mathrm{C}$ & $\mathrm{C}$ \\
\hline$R_{17}$ & B & B & B & B & B & $\mathrm{C}$ & $R_{17}$ & A & A & A & A & A & A \\
\hline$R_{18}$ & B & B & B & B & B & $\mathrm{C}$ & $R_{18}$ & B & B & B & B & B & B \\
\hline$R_{19}$ & B & B & B & B & B & B & $R_{19}$ & B & B & B & B & B & B \\
\hline$R_{20}$ & B & B & B & B & B & $\mathrm{C}$ & $R_{20}$ & A & A & A & A & A & A \\
\hline$R_{21}$ & $\mathrm{D}$ & $\mathrm{D}$ & $\mathrm{D}$ & $\mathrm{D}$ & $\mathrm{D}$ & $\mathrm{D}$ & $R_{21}$ & B & B & B & B & B & B \\
\hline$R_{22}$ & $\mathrm{C}$ & $\mathrm{C}$ & $\mathrm{C}$ & $\mathrm{C}$ & $\mathrm{C}$ & $\mathrm{C}$ & $R_{22}$ & B & B & B & B & B & B \\
\hline$R_{23}$ & $\mathrm{C}$ & $\mathrm{C}$ & $\mathrm{C}$ & $\mathrm{C}$ & $\mathrm{C}$ & $\mathrm{C}$ & $R_{23}$ & B & B & B & B & B & B \\
\hline
\end{tabular}

\section{Discussion of results and implications for management}

Various practical considerations and useful management implications may be derived by analysing the obtained results. The first observation is related to the robustness of results by varying the cutting level. The cutting level $\lambda$ indicates whether the credibility degree of the analysed outranking relations is sufficiently enough to establish an outranking conclusion regarding the comparison between an alternative and a reference profile [63]. $\lambda$ may be interpreted as the required majority of criteria weights in favor of a specific outranking needed to accept that conclusion. We can appreciate as, by progressively increasing the value of $\lambda$ within the interval $[0.5,1]$, the pessimistic procedure tends to assign SCRs to lower priority classes whereas, on the contrary, the optimistic procedure tends to assign SCRs to higher priority classes. In any case, we can observe as there are some SCRs assigned to the same class independently on the value assumed by the cutting level. This is, for the example, the case of $R_{19}$ (inefficient delivery of 
Table 3 Analysing the influence of thresholds on the final assignment (optimistic procedure)

\begin{tabular}{llllllllllllll}
\hline $\mathrm{SCR} / \lambda$ & 0.50 & 0.60 & 0.70 & 0.80 & 0.90 & 1.00 & $\mathrm{SCR} / \lambda$ & 0.50 & 0.60 & 0.70 & 0.80 & 0.90 & 1.00
\end{tabular}

(a) $V_{k}$ equal to 0.5 times the width of classes

(b) $V_{k}$ equal to 0.75 times the width of classes

$\begin{array}{llllllllllllll}R_{1} & \mathrm{~A} & \mathrm{~A} & \mathrm{~A} & \mathrm{~A} & \mathrm{~A} & \mathrm{~A} & R_{1} & \mathrm{~B} & \mathrm{~B} & \mathrm{~B} & \mathrm{~B} & \mathrm{~B} & \mathrm{~A}\end{array}$

$\begin{array}{llllllllllllll}R_{2} & \mathrm{~B} & \mathrm{~B} & \mathrm{~B} & \mathrm{~B} & \mathrm{~B} & \mathrm{~B} & R_{2} & \mathrm{C} & \mathrm{C} & \mathrm{B} & \mathrm{B} & \mathrm{B} & \mathrm{B}\end{array}$

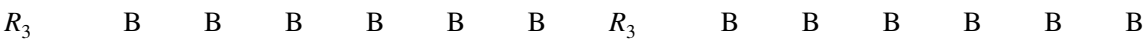

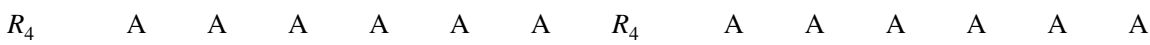

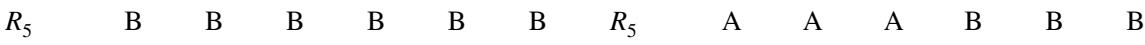

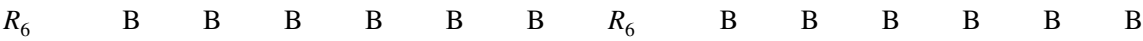

$\begin{array}{llllllllllllllll}R_{7} & \mathrm{~B} & \mathrm{~B} & \mathrm{~B} & \mathrm{~B} & \mathrm{~B} & \mathrm{~B} & R_{7} & \mathrm{~B} & \mathrm{~B} & \mathrm{~B} & \mathrm{~B} & \mathrm{~B} & \mathrm{~B}\end{array}$

$\begin{array}{llllllllllllll}R_{8} & \mathrm{~B} & \mathrm{~B} & \mathrm{~B} & \mathrm{~B} & \mathrm{~B} & \mathrm{~B} & R_{8} & \mathrm{~B} & \mathrm{~B} & \mathrm{~B} & \mathrm{~B} & \mathrm{~B} & \mathrm{~B}\end{array}$

$\begin{array}{llllllllllllll}R_{9} & \mathrm{~B} & \mathrm{~B} & \mathrm{~B} & \mathrm{~B} & \mathrm{~B} & \mathrm{~B} & R_{9} & \mathrm{~B} & \mathrm{~B} & \mathrm{~B} & \mathrm{~B} & \mathrm{~B} & \mathrm{~B}\end{array}$

$\begin{array}{llllllllllllllll}R_{10} & \mathrm{~B} & \mathrm{~B} & \mathrm{~B} & \mathrm{~B} & \mathrm{~B} & \mathrm{~B} & R_{10} & \mathrm{~B} & \mathrm{~B} & \mathrm{~B} & \mathrm{~B} & \mathrm{~B} & \mathrm{~B}\end{array}$

$\begin{array}{llllllllllllll}R_{11} & \mathrm{~B} & \mathrm{~B} & \mathrm{~B} & \mathrm{~B} & \mathrm{~B} & \mathrm{~B} & R_{11} & \mathrm{~B} & \mathrm{~B} & \mathrm{~B} & \mathrm{~B} & \mathrm{~B} & \mathrm{~B}\end{array}$

$\begin{array}{llllllllllllll}R_{12} & \mathrm{~B} & \mathrm{~B} & \mathrm{~B} & \mathrm{~B} & \mathrm{~B} & \mathrm{~B} & R_{12} & \mathrm{~B} & \mathrm{~B} & \mathrm{~B} & \mathrm{~B} & \mathrm{~B} & \mathrm{~B}\end{array}$

$\begin{array}{llllllllllllll}R_{13} & \mathrm{~B} & \mathrm{~B} & \mathrm{~B} & \mathrm{~B} & \mathrm{~B} & \mathrm{~B} & R_{13} & \mathrm{~B} & \mathrm{~B} & \mathrm{~B} & \mathrm{~B} & \mathrm{~B} & \mathrm{~B}\end{array}$

$\begin{array}{llllllllllllll}R_{14} & \mathrm{C} & \mathrm{C} & \mathrm{B} & \mathrm{B} & \mathrm{B} & \mathrm{B} & R_{14} & \mathrm{C} & \mathrm{C} & \mathrm{C} & \mathrm{C} & \mathrm{B} & \mathrm{B}\end{array}$

$\begin{array}{llllllllllllll}R_{15} & \mathrm{~B} & \mathrm{~B} & \mathrm{~B} & \mathrm{~B} & \mathrm{~B} & \mathrm{~B} & R_{15} & \mathrm{~B} & \mathrm{~B} & \mathrm{~B} & \mathrm{~B} & \mathrm{~B} & \mathrm{~B}\end{array}$

$\begin{array}{lllllllllllllllll}R_{16} & \mathrm{C} & \mathrm{C} & \mathrm{C} & \mathrm{C} & \mathrm{C} & \mathrm{C} & R_{16} & \mathrm{C} & \mathrm{C} & \mathrm{C} & \mathrm{C} & \mathrm{C} & \mathrm{C}\end{array}$

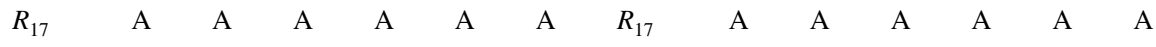

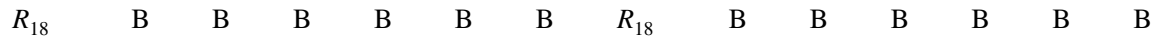

$\begin{array}{llllllllllllll}R_{19} & \mathrm{~B} & \mathrm{~B} & \mathrm{~B} & \mathrm{~B} & \mathrm{~B} & \mathrm{~B} & R_{19} & \mathrm{~B} & \mathrm{~B} & \mathrm{~B} & \mathrm{~B} & \mathrm{~B} & \mathrm{~B}\end{array}$

$\begin{array}{llllllllllllll}R_{20} & \mathrm{~A} & \mathrm{~A} & \mathrm{~A} & \mathrm{~A} & \mathrm{~A} & \mathrm{~A} & R_{20} & \mathrm{~A} & \mathrm{~A} & \mathrm{~A} & \mathrm{~A} & \mathrm{~A} & \mathrm{~A}\end{array}$

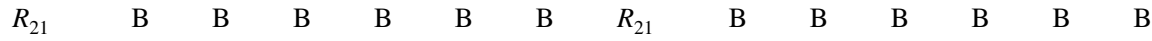

$\begin{array}{llllllllllllll}R_{22} & \mathrm{~B} & \mathrm{~B} & \mathrm{~B} & \mathrm{~B} & \mathrm{~B} & \mathrm{~B} & R_{22} & \mathrm{~B} & \mathrm{~B} & \mathrm{~B} & \mathrm{~B} & \mathrm{~B} & \mathrm{~A}\end{array}$

\begin{tabular}{llllllllllllll}
$R_{23}$ & $\mathrm{~A}$ & $\mathrm{~A}$ & $\mathrm{~A}$ & $\mathrm{~A}$ & $\mathrm{~A}$ & $\mathrm{~A}$ & $R_{23}$ & $\mathrm{~B}$ & $\mathrm{~B}$ & $\mathrm{~B}$ & $\mathrm{~B}$ & $\mathrm{~B}$ & $\mathrm{~A}$ \\
\hline $\mathrm{SCR} / \lambda$ & 0.50 & 0.60 & 0.70 & 0.80 & 0.90 & 1.00 & $\mathrm{SCR} / \lambda$ & 0.50 & 0.60 & 0.70 & 0.80 & 0.90 & 1.00
\end{tabular}

(c) $V_{k}$ equal to 1.25 times the width of classes

(d) $V_{k}$ equal to 1.5 times the width of classes

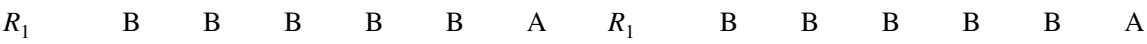

$\begin{array}{lllllllllllllll}R_{2} & \mathrm{C} & \mathrm{C} & \mathrm{B} & \mathrm{B} & \mathrm{B} & \mathrm{B} & R_{2} & \mathrm{C} & \mathrm{C} & \mathrm{C} & \mathrm{B} & \mathrm{B} & \mathrm{B}\end{array}$

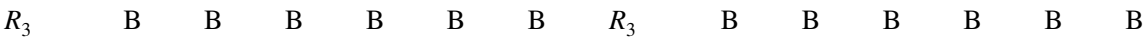

$\begin{array}{lllllllllllllll}R_{4} & \mathrm{~A} & \mathrm{~A} & \mathrm{~A} & \mathrm{~A} & \mathrm{~A} & \mathrm{~A} & R_{4} & \mathrm{~B} & \mathrm{~B} & \mathrm{~A} & \mathrm{~A} & \mathrm{~A} & \mathrm{~A}\end{array}$

$\begin{array}{llllllllllllll}R_{5} & \mathrm{~A} & \mathrm{~A} & \mathrm{~A} & \mathrm{~B} & \mathrm{~B} & \mathrm{~B} & R_{5} & \mathrm{~A} & \mathrm{~A} & \mathrm{~A} & \mathrm{~A} & \mathrm{~B} & \mathrm{~B}\end{array}$

$\begin{array}{llllllllllllll}R_{6} & \mathrm{~B} & \mathrm{~B} & \mathrm{~B} & \mathrm{~B} & \mathrm{~B} & \mathrm{~B} & R_{6} & \mathrm{~B} & \mathrm{~B} & \mathrm{~B} & \mathrm{~B} & \mathrm{~B} & \mathrm{~B}\end{array}$

$\begin{array}{llllllllllllll}R_{7} & \mathrm{C} & \mathrm{C} & \mathrm{C} & \mathrm{B} & \mathrm{B} & \mathrm{B} & R_{7} & \mathrm{C} & \mathrm{C} & \mathrm{C} & \mathrm{C} & \mathrm{B} & \mathrm{B}\end{array}$

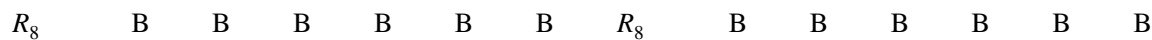

$\begin{array}{llllllllllllll}R_{9} & \mathrm{~B} & \mathrm{~B} & \mathrm{~B} & \mathrm{~B} & \mathrm{~B} & \mathrm{~B} & R_{9} & \mathrm{~B} & \mathrm{~B} & \mathrm{~B} & \mathrm{~B} & \mathrm{~B} & \mathrm{~B}\end{array}$

$\begin{array}{llllllllllllll}R_{10} & \mathrm{~B} & \mathrm{~B} & \mathrm{~B} & \mathrm{~B} & \mathrm{~B} & \mathrm{~B} & R_{10} & \mathrm{~A} & \mathrm{~A} & \mathrm{~A} & \mathrm{~B} & \mathrm{~B} & \mathrm{~B}\end{array}$

$\begin{array}{lllllllllllllll}R_{11} & \mathrm{C} & \mathrm{B} & \mathrm{B} & \mathrm{B} & \mathrm{B} & \mathrm{B} & R_{11} & \mathrm{~B} & \mathrm{C} & \mathrm{B} & \mathrm{B} & \mathrm{B} & \mathrm{B}\end{array}$

$\begin{array}{llllllllllllll}R_{12} & \mathrm{~B} & \mathrm{~B} & \mathrm{~B} & \mathrm{~B} & \mathrm{~B} & \mathrm{~B} & R_{12} & \mathrm{~B} & \mathrm{~B} & \mathrm{~B} & \mathrm{~B} & \mathrm{~B} & \mathrm{~B}\end{array}$

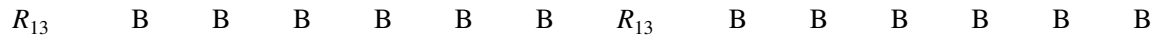

$\begin{array}{lllllllllllllll}R_{14} & \mathrm{~B} & \mathrm{~B} & \mathrm{C} & \mathrm{C} & \mathrm{C} & \mathrm{B} & R_{14} & \mathrm{~B} & \mathrm{~B} & \mathrm{C} & \mathrm{C} & \mathrm{C} & \mathrm{B}\end{array}$

$\begin{array}{llllllllllllll}R_{15} & \mathrm{~B} & \mathrm{~B} & \mathrm{~B} & \mathrm{~B} & \mathrm{~B} & \mathrm{~B} & R_{15} & \mathrm{~B} & \mathrm{~B} & \mathrm{~B} & \mathrm{~B} & \mathrm{~B} & \mathrm{~B}\end{array}$

$\begin{array}{llllllllllllll}R_{16} & \mathrm{~B} & \mathrm{~B} & \mathrm{C} & \mathrm{C} & \mathrm{C} & \mathrm{C} & R_{16} & \mathrm{~B} & \mathrm{~B} & \mathrm{C} & \mathrm{C} & \mathrm{C} & \mathrm{C}\end{array}$ 
Table 3 (continued)

\begin{tabular}{llllllllllllll}
\hline $\mathrm{SCR} / \lambda$ & 0.50 & 0.60 & 0.70 & 0.80 & 0.90 & 1.00 & $\mathrm{SCR} / \lambda$ & 0.50 & 0.60 & 0.70 & 0.80 & 0.90 & 1.00 \\
\hline$R_{17}$ & $\mathrm{~B}$ & $\mathrm{~B}$ & $\mathrm{~A}$ & $\mathrm{~A}$ & $\mathrm{~A}$ & $\mathrm{~A}$ & $R_{17}$ & $\mathrm{~B}$ & $\mathrm{~B}$ & $\mathrm{~A}$ & $\mathrm{~A}$ & $\mathrm{~A}$ & $\mathrm{~A}$ \\
$R_{18}$ & $\mathrm{~B}$ & $\mathrm{~B}$ & $\mathrm{~B}$ & $\mathrm{~B}$ & $\mathrm{~B}$ & $\mathrm{~B}$ & $R_{18}$ & $\mathrm{~B}$ & $\mathrm{~B}$ & $\mathrm{~B}$ & $\mathrm{~B}$ & $\mathrm{~B}$ & $\mathrm{~B}$ \\
$R_{19}$ & $\mathrm{~B}$ & $\mathrm{~B}$ & $\mathrm{~B}$ & $\mathrm{~B}$ & $\mathrm{~B}$ & $\mathrm{~B}$ & $R_{19}$ & $\mathrm{~B}$ & $\mathrm{~B}$ & $\mathrm{~B}$ & $\mathrm{~B}$ & $\mathrm{~B}$ & $\mathrm{~B}$ \\
$R_{20}$ & $\mathrm{~B}$ & $\mathrm{~B}$ & $\mathrm{~A}$ & $\mathrm{~A}$ & $\mathrm{~A}$ & $\mathrm{~A}$ & $R_{20}$ & $\mathrm{~B}$ & $\mathrm{~B}$ & $\mathrm{~A}$ & $\mathrm{~A}$ & $\mathrm{~A}$ & $\mathrm{~A}$ \\
$R_{21}$ & $\mathrm{C}$ & $\mathrm{C}$ & $\mathrm{C}$ & $\mathrm{C}$ & $\mathrm{B}$ & $\mathrm{B}$ & $R_{21}$ & $\mathrm{C}$ & $\mathrm{C}$ & $\mathrm{C}$ & $\mathrm{C}$ & $\mathrm{B}$ & $\mathrm{B}$ \\
$R_{22}$ & $\mathrm{~B}$ & $\mathrm{~B}$ & $\mathrm{~B}$ & $\mathrm{~B}$ & $\mathrm{~B}$ & $\mathrm{~B}$ & $R_{22}$ & $\mathrm{~B}$ & $\mathrm{C}$ & $\mathrm{C}$ & $\mathrm{C}$ & $\mathrm{B}$ & $\mathrm{B}$ \\
$R_{23}$ & $\mathrm{~B}$ & $\mathrm{~B}$ & $\mathrm{~B}$ & $\mathrm{~B}$ & $\mathrm{~B}$ & $\mathrm{~B}$ & $R_{23}$ & $\mathrm{~B}$ & $\mathrm{~B}$ & $\mathrm{~B}$ & $\mathrm{~B}$ & $\mathrm{~B}$ & $\mathrm{~B}$ \\
\hline
\end{tabular}

products), which is always assigned to class B (medium-high priority risk) for any value of $\lambda$ and also by varying the indifference, preference and veto thresholds.

Results obtained via the chosen optimistic procedure (Table $2 \mathrm{~b}$ ) underline as certain SCRs definitely need to be managed with priority, being consistently assigned to class $\mathrm{A}$. This is the case of $R_{4}$ (requirement accomplishment), $R_{17}$ (facilities, $\mathrm{HR}$, policies and processes breakdown) and $R_{20}$ (supply chain disruptions due to natural disasters). Proper mitigation and/or preventive interventions should be aimed at reducing the evaluation of criteria given in Table 1, with special regard to those criteria which have associated higher weights. For example, in the case of $R_{17}$, proper measures should aim to reduce the dependence with other SCRs by separating processes and resources, but also such aspects as the strategic impact and the cost derived by the risk occurrence. To make another example, risks $R_{20}$ (supply chain disruptions due to natural disasters) and $R_{4}$ (requirement accomplishment) reveal to be particular important in present times afflicted by the COVID-19 outbreak. The impact of such risks can be reduced by implementing, for instance, efficient strategies of supplier selection to limit the possibility of production breakdown then an excessive cost exposure. This topic will be the objective of further research. Among the risks assigned to class B (medium-high priority), we can observe as $R_{1}$ is upgraded to class A when the cutting level is maximum. It means that it has associated a higher criteria evaluation (the associated cost evaluation is indeed quite high) with respect to the other SCRs assigned to class B; this is the reason why, after dealing with the risks assigned to class A, major priority should be given to $R_{1}$ within class $\mathrm{B}$. When it comes to the risks assigned to the class $\mathrm{C}$ (medium-low priority), results tell us that $R_{14}$ (production breakdown) and $R_{16}$ (matching supplier requirements) are the less urgent. Management interventions for these risks can be postponed.

Regarding significant differences with our previous work (Mzougui et al., 2020), the topics are certainly interconnected but treated from different perspectives and by means of different methodological approaches. Instead of merely ranking supply chain risks, ELECTRE TRI proceeds by sorting these risks into classes expressing priority of intervention according to the considered set of evaluation criteria and their assigned weights. This procedure permits to support the company management in identifying which set of supply chain risks, among those formalised through a previous stage of risk identification, has a stronger influence on system functioning 
on the basis of the classes in which those risks will be sorted by the mentioned MCDM.

The present application hence represents a further step from the previous risk ranking for an effective SCR management in the field of automotive industry inspired by the philosophy of continuous improvement. We have also showed as, with respect to the SCRs ranking, the assignment to ordered priority classes carried out by means of the sorting procedure ELECTRE TRI offers more structured management insights. This application makes it easier the immediate identification of the highly critical risks belonging to a wider SCR set, so that implementing more focused risk management actions can be possible.

\section{Conclusions and future works}

The present paper deals with the topic of complex supply network management and, in particular, with the SCRM, which has paramount importance in business. We specifically propose a structured MCDM approach making use of the sorting technique ELECTRE TRI to assign SCRs to ordered classes on the basis of their required priority of intervention, and to move forward with respect to the process of SCRs ranking. When risks are assigned to classes, it can be much easier to immediately identify which aspects require immediate interventions aimed at optimising risk management. The approach is applied to a real-world case study in the field of the automotive industry and various scenarios of analysis have been explored to confirm the robustness of results. The procedure carried out in the present paper is perfectly suitable to deal with those situations in which the number of SCRs to be taken into account is huge.

Possible future developments of the present research may refer to the implementation of a structured framework capable of easing the selection of the best supplier/s on the basis of specific risk requirements.

\section{References}

1. Abdel-Basset, M., Gunasekaran, M., Mohamed, M., Chilamkurti, N.: A framework for risk assessment, management and evaluation: economic tool for quantifying risks in supply chain. Future Generation Comput. Syst. 90, 489-502 (2019)

2. Akram, M., Ilyas, F., Garg, H.: Multi-criteria group decision making based on electre i method in pythagorean fuzzy information. Soft Comput. 24(5), 3425-3453 (2020)

3. Altay, N., Gunasekaran, A., Dubey, R., Childe, S.J.: Agility and resilience as antecedents of supply chain performance under moderating effects of organizational culture within the humanitarian setting: a dynamic capability view. Prod. Plan. Control 29(14), 1158-1174 (2018)

4. Awoyemi, B.S., Alfa, A.S., Maharaj, B.T.: Network restoration for next-generation communication and computing networks. J. Comput. Netw. Commun. 2018 (2018)

5. Bharsakade, R.S., Acharya, P., Ganapathy, L., Tiwari, M.K.: A lean approach to healthcare management using multi criteria decision making. Opsearch, 1-26 (2021)

6. Bhutta, K.S., Huq, F.: Supplier selection problem: a comparison of the total cost of ownership and analytic hierarchy process approaches. Supp. Chain Manage. Int. J. (2002) 
7. Carpitella, S., Ocaña-Levario, S.J., Benítez, J., Certa, A., Izquierdo, J.: A hybrid multi-criteria approach to gpr image mining applied to water supply system maintenance. J. Appl. Geophys. 159, 754-764 (2018)

8. Carpitella, S., Herrera, M., Certa, A., Izquierdo, J.: Updating the ospf routing protocol for communication networks by optimal decision-making over the k-shortest path algorithm. Modell. Eng. Human Behav. 2019, 118 (2019)

9. Carpitella, S., Certa, A., Izquierdo, J., La Cascia, M.: Multi-criteria decision-making approach for modular enterprise resource planning sorting problems. J. Multi-Criteria Decis. Anal. (2021) (in press)

10. Certa, A., Carpitella, S., Enea, M., Micale, R.: A multi criteria decision making approach to support the risk management: a case study. In: Proceedings of the 21th Summer School "Francesco Turco", Naples, Italy, September, pp. 13-15 (2016)

11. Chand, M., Raj, T., Shankar, R., Agarwal, A.: Select the best supply chain by risk analysis for indian industries environment using mcdm approaches. Int. J. Benchmark. (2017)

12. Chang, K.-H., Cheng, C.-H.: Evaluating the risk of failure using the fuzzy owa and dematel method. J. Intell. Manufact. 22(2), 113-129 (2011)

13. Chopra, S., Meindl, P., Kalra, D.V.: Supply Chain Management: Strategy, Planning, and Operation, vol. 232. Pearson, Boston, MA (2013)

14. Christopher, M., Mena, C., Khan, O., Yurt, O.: Approaches to managing global sourcing risk. Supp. Chain Manage. Int. J. (2011)

15. Chu, C.-Y., Park, K., Kremer, G.E.: A global supply chain risk management framework: an application of text-mining to identify region-specific supply chain risks. Adv. Eng. Inform. 45, 101053 (2020)

16. Committee, I.T., et al.: Analysis techniques for system reliability-procedure for failure mode and effects analysis (fmea). IEC 60812 (2006)

17. Creazza, A., Colicchia, C., Spiezia, S., Dallari, F.: Who cares? supply chain managers' perceptions regarding cyber supply chain risk management in the digital transformation era. Supply Chain Manage. Int. J. (2021)

18. Curkovic, S., Scannell, T., Wagner, B.: Using fmea for supply chain risk management. Modern Manage. Sci. Eng. 1(2), 251-265 (2013)

19. Fan, Y., Stevenson, M.: A review of supply chain risk management: definition, theory, and research agenda. Int. J. Phys. Distrib. Logist. Manage. (2018)

20. Garvey, M.D., Carnovale, S.: The rippled newsvendor: a new inventory framework for modelling supply chain risk severity in the presence of risk propagation. Int. J. Prod. Econ. 107752 (2020)

21. Gaudenzi, B., Borghesi, A.: Managing risks in the supply chain using the ahp method. Int. J. Logist. Manage. (2006)

22. Ghadge, A., Dani, S., Kalawsky, R.: Supply chain risk management: present and future scope. Int. J. logist. Manage. (2012)

23. Ghasimi, S.A., Ramli, R., Saibani, N.: A genetic algorithm for optimizing defective goods supply chain costs using jit logistics and each-cycle lengths. Appl. Math. Modell. 38(4), 1534-1547 (2014)

24. Giannakis, M., Papadopoulos, T.: Supply chain sustainability: a risk management approach. Int. J. Prod. Econ. 171, 455-470 (2016)

25. Gonçalves, A.T.P., Araújo, M.V.P.d., Mól, A.L.R., Rocha, F.A.F.d.: Application of the electre tri method for supplier classification in supply chains. Pesquisa Operacional 41 (2021)

26. Govindan, K., Khodaverdi, R., Vafadarnikjoo, A.: Intuitionistic fuzzy based dematel method for developing green practices and performances in a green supply chain. Exp. Syst. Appl. 42(20), 7207-7220 (2015)

27. Habib, K., Sprecher, B., Young, S.B.: Covid-19 impacts on metal supply: how does 2020 differ from previous supply chain disruptions? Resour. Conserv. Recycling 165, 105229 (2020)

28. Haren, P., Simchi-Levi, D.: How coronavirus could impact the global supply chain by mid-march. Harvard Bus. Rev. 28 (2020)

29. Hegde, S., Koolagudi, S.G., Bhattacharya, S.: Path restoration in source routed software defined networks. In: 2017 Ninth International Conference on Ubiquitous and Future Networks (ICUFN), pp. 720-725. IEEE (2017)

30. Heidari, S.S., Khanbabaei, M., Sabzehparvar, M.: A model for supply chain risk management in the automotive industry using fuzzy analytic hierarchy process and fuzzy topsis. Benchmark. Int. J. (2018) 
31. Ho, W., Zheng, T., Yildiz, H., Talluri, S.: Supply chain risk management: a literature review. Int. J. Prod. Res. 53(16), 5031-5069 (2015)

32. Jiang, B., Baker, R.C., Frazier, G.V.: An analysis of job dissatisfaction and turnover to reduce global supply chain risk: evidence from china. J. Oper. Manage. 27(2), 169-184 (2009)

33. Junaid, M., Xue, Y., Syed, M.W., Li, J.Z., Ziaullah, M.: A neutrosophic ahp and topsis framework for supply chain risk assessment in automotive industry of pakistan. Sustainability 12(1), 154 (2020)

34. Karmaker, C.L., Ahmed, T., Ahmed, S., Ali, S.M., Moktadir, M.A., Kabir, G.: Improving supply chain sustainability in the context of covid-19 pandemic in an emerging economy: exploring drivers using an integrated model. Sustain. Prod. Consump. (2020)

35. Kim, S.C., Shin, K.S.: Negotiation model for optimal replenishment planning considering defects under the vmi and jit environment. Asian J. Ship. Logisit. 35(3), 147-153 (2019)

36. Kuipers, F.A.: An overview of algorithms for network survivability. Int. Scholar. Res. Notices 2012 (2012)

37. Kumar, A., Sah, B., Singh, A.R., Deng, Y., He, X., Kumar, P., Bansal, R.: A review of multi criteria decision making $(\mathrm{mcdm})$ towards sustainable renewable energy development. Renew. Sustain. Energy Rev. 69, 596-609 (2017a)

38. Kumar, D., Garg, C.P.: Evaluating sustainable supply chain indicators using fuzzy ahp. Benchmark. Int. J. (2017)

39. Kumar, P., Singh, R.K., Vaish, A.: Suppliers' green performance evaluation using fuzzy extended electre approach. Clean Technol. Environ. Policy 19(3), 809-821 (2017b)

40. Kumar, V., Vrat, P., Shankar, R.: Prioritization of strategies to overcome the barriers in industry 4.0: a hybrid mcdm approach. Opsearch, 1-40 (2021)

41. Lau, H., Tsang, Y.P., Nakandala, D., Lee, C.K.: Risk quantification in cold chain management: a federated learning-enabled multi-criteria decision-making methodology. Indus. Manage. Data Syst. (2021)

42. Levner, E., Ptuskin, A.: An entropy-based approach to identifying vulnerable components in a supply chain. Int. J. Prod. Res. 53(22), 6888-6902 (2015)

43. Lian, J., Zhang, Y., Li, C.J.: An efficient k-shortest paths based routing algorithm. Adv. Mater. Res. 532, 1775-1779 (2012) (Trans Tech Publ)

44. Liu, C.-L., Lee, M.-Y.: Integration, supply chain resilience, and service performance in third-party logistics providers. Int. J. Logist. Manage. (2018)

45. Liu, Z., Ming, X.: A methodological framework with rough-entropy-electre tri to classify failure modes for co-implementation of smart pss. Adv. Eng. Inform. 42, 100968 (2019)

46. Louis, M., Pagell, M.: Categorizing supply chain risks: review, integrated typology and future research. In: Revisiting Supply Chain Risk, pp 329-366. Springer (2019)

47. Mentzer, J.T., DeWitt, W., Keebler, J.S., Min, S., Nix, N.W., Smith, C.D., Zacharia, Z.G.: Defining supply chain management. J. Bus. Logist. 22(2), 1-25 (2001)

48. Merad, M., Verdel, T., Roy, B., Kouniali, S.: Use of multi-criteria decision-aids for risk zoning and management of large area subjected to mining-induced hazards. Tunnelling Underground Space Technol. 19(2), 125-138 (2004)

49. Merzifonluoglu, Y.: Impact of risk aversion and backup supplier on sourcing decisions of a firm. Int. J. Prod. Res. 53(22), 6937-6961 (2015)

50. Mogale, D., Kumar, S.K., Tiwari, M.K.: Green food supply chain design considering risk and postharvest losses: a case study. Ann. Oper. Res. 295, 257-284 (2020)

51. Moktadir, M.A., Ali, S.M., Mangla, S.K., Sharmy, T.A., Luthra, S., Mishra, N., Garza-Reyes, J.A.: Decision modeling of risks in pharmaceutical supply chains. Indus. Manage. Data Syst. (2018)

52. Moktadir, M.A., Dwivedi, A., Khan, N.S., Paul, S.K., Khan, S.A., Ahmed, S., Sultana, R.: Analysis of risk factors in sustainable supply chain management in an emerging economy of leather industry. $\mathrm{J}$. Cleaner Prod. 124641 (2020)

53. Mousseau, V., Slowinski, R., Zielniewicz, P.: A user-oriented implementation of the electre-tri method integrating preference elicitation support. Comput. Oper. Res. 27(7-8), 757-777 (2000)

54. Muhammad, M.N., Cavus, N.: Fuzzy dematel method for identifying $1 m$ s evaluation criteria. Procedia Comput. Sci. 120, 742-749 (2017)

55. Mulliner, E., Malys, N., Maliene, V.: Comparative analysis of mcdm methods for the assessment of sustainable housing affordability. Omega 59, 146-156 (2016)

56. Munir, M., Jajja, M.S.S., Chatha, K.A., Farooq, S.: Supply chain risk management and operational performance: the enabling role of supply chain integration. Int. J. Prod. Econ. 227, 107667 (2020)

57. Mzougui, I., Carpitella, S., Certa, A., Felsoufi, Z.E., Izquierdo, J.: Assessing supply chain risks in the automotive industry through a modified mcdm-based fmeca. Processes 8(5), 579 (2020) 
58. Neiger, D., Rotaru, K., Churilov, L.: Supply chain risk identification with value-focused process engineering. J. Oper. Manage. 27(2), 154-168 (2009)

59. Norrman, A., Jansson, U.: Ericsson's proactive supply chain risk management approach after a serious sub-supplier accident. Int. J. Phys. Distrib. Logist. Manage. (2004)

60. Radivojević, G., Gajović, V.: Supply chain risk modeling by ahp and fuzzy ahp methods. J. Risk Res. 17(3), 337-352 (2014)

61. Raihan, A.S., Ali, S.M., Roy, S., Das, M., Kabir, G., Paul, S.K.: Integrated model for soft drink industry supply chain risk assessment: implications for sustainability in emerging economies. Int. J. Fuzzy Syst. 1-22 (2021)

62. Rezaei, S., Ghalehkhondabi, I., Rafiee, M., Zanganeh, S.N., et al.: Supplier selection and order allocation in clsc configuration with various supply strategies under disruption risk. Opsearch 57(3), 908-934 (2020)

63. Rocha, C., Dias, L.C.: An algorithm for ordinal sorting based on electre with categories defined by examples. J. Global Optim. 42(2), 255-277 (2008)

64. Rostamzadeh, R., Ghorabaee, M.K., Govindan, K., Esmaeili, A., Nobar, H.B.K.: Evaluation of sustainable supply chain risk management using an integrated fuzzy topsis-critic approach. J. Cleaner Prod. 175, 651-669 (2018)

65. Sahu, N.K., Sahu, A.K., Sahu, A.K.: Appraisement and benchmarking of third-party logistic service provider by exploration of risk-based approach. Cogent Bus. Manage. 2(1), 1121637 (2015)

66. Sahu, N.K., Sahu, A.K., Sahu, A.K.: Fuzzy-ahp: a boon in 3pl decision making process. In: Theoretical and practical advancements for fuzzy system integration, pp. 97-125. IGI Global (2017)

67. Samvedi, A., Jain, V., Chan, F.T.: Quantifying risks in a supply chain through integration of fuzzy ahp and fuzzy topsis. Int. J. Prod. Res. 51(8), 2433-2442 (2013)

68. Schoenherr, T., Tummala, V.R., Harrison, T.P.: Assessing supply chain risks with the analytic hierarchy process: providing decision support for the offshoring decision by a us manufacturing company. J. Purchas. Supp. Manage. 14(2), 100-111 (2008)

69. Smialek, J., Tankersley, J.: Fed makes emergency rate cut, but markets continue tumbling. New York Times (2020)

70. Sodhi, M.S., Son, B.-G., Tang, C.S.: Researchers' perspectives on supply chain risk management. Prod. Oper. Manage. 21(1), 1-13 (2012)

71. Tang, C., Tomlin, B.: The power of flexibility for mitigating supply chain risks. Int. J. Prod. Econ. 116(1), 12-27 (2008)

72. Thun, J.-H., Hoenig, D.: An empirical analysis of supply chain risk management in the german automotive industry. Int. J. Prod. Econ. 131(1), 242-249 (2011)

73. Trkman, P., de Oliveira, M.P.V., McCormack, K.: Value-oriented supply chain risk management: you get what you expect. Indus. Manage. Data Syst. (2016)

74. Uddin, S., Ali, S., Kabir, G., Suhi, S., Enayet, R., Haque, T.: An ahp-electre framework to evaluate barriers to green supply chain management in the leather industry. Int. J. Sustain. Dev. World Ecol. 26(8), 732-751 (2019)

75. Vanalle, R.M., Lucato, Ganga, Filho, W.G., Alves, A.: Risk management in the automotive supply chain: an exploratory study in brazil. Int. J. Prod. Res. 58(3), 783-799 (2020)

76. Vargas, L., De Felice, F., Petrillo, A.: Editorial journal of multicriteria decision analysis special issue on "industrial and manufacturing engineering: theory and application using ahp/anp." J. Multi Criteria Decis. Anal. 24(5-6), 201-202 (2017)

77. Wang, H., Gu, T., Jin, M., Zhao, R., Wang, G.: The complexity measurement and evolution analysis of supply chain network under disruption risks. Chaos Solit. Fract. 116, 72-78 (2018)

78. Wilding, R., Wagner, B., Colicchia, C., Strozzi, F.: Supply chain risk management: a new methodology for a systematic literature review. Supp. Chain Manage. Int. J. (2012)

79. Xie, C., Anumba, C.J., Lee, T.-R., Tummala, R., Schoenherr, T.: Assessing and managing risks using the supply chain risk management process (scrmp). Supp. Chain Manage. Int. J. (2011)

80. Yang, J., Xie, H., Yu, G., Liu, M.: Achieving a just-in-time supply chain: the role of supply chain intelligence. Int. J. Prod. Econ. 231, 107878 (2021)

Publisher's Note Springer Nature remains neutral with regard to jurisdictional claims in published maps and institutional affiliations. 